УДК 004.05

\author{
[0000-0002-0009-337х] С. В. Сисоєнко, к.т.н., \\ e-mail: s.sysoienko@gmail.com \\ Д. В. Дахненко, магістрант \\ e-mail: dahnenko02501@gmail.com \\ Черкаський державний технологічний університет \\ б-р Шевченка, 460, м. Черкаси, 18000, Україна
}

\title{
ОПТИМІЗАЦІЯ ФУНКЦІОНАЛЬНИХ МОЖЛИВОСТЕЙ ІНФОРМАЦЙНОЇ СИСТЕМИ ДЛЯ РОЗВИТКУ ТУРИЗМУ
}

Проведене дослідження дало можливість оптимізувати функиіональний потениіал інформаційної автоматизованої системи для розвитку туризму. Дослідження показало, що одним із важливих факторів у проведенні оптимізаиії є швидкість завантаження сторінок та обробки даних з боку сервера. В результаті дослідження та оптимізаиії було отримано статистику відвідуваності ијієі системи, а також ефективність ї̈ використання, виявлено основні переваги та недоліки.

Ключові слова: оптимізачія, дослідження, система для розвитку туризму, статистика, база даних, авторизачія, рефакторинг.

Вступ. У статті приділено увагу дослідженню та оптимізації функціональних можливостей системи для розвитку туризму за допомогою проведення аналізу відвідуваності системи, дослідження ефективності обробки даних з боку сервера.

Існує багато процесів і аспектів, які необхідно враховувати при виборі, розробці, тестуванні, впровадженні та підтримці цілісної системи. Проте аналіз технічної літератури, наукових статей показав, що система має значну кількість вразливих місць, які потрібно оптимізувати та вдосконалити.

Аналіз останніх досліджень та публікацій. Аналізуючи стан та враховуючи просторовий аспект застосування інформаційних технологій у туризмі $[1,2,3]$, було визначено, що досить вагомим і перспективним стає застосування сучасних мультимедійних технологій.

Провадження та організація туристичних послуг, що пов'язані зі щорічним збільшенням кількості туристичних послуг, географічно далеких одна від одної, системою відносин суб'єктів туристичного ринку, яка постійно збільшується, різноманітність типів туризму викликають необхідність дослідження й оптимізацію функціональних можливостей інформаційної системи для розвитку туризму [4].

На сьогоднішній день туризм став невід'ємною галуззю кожної країни світу, тому що це - одна $з$ найбільш прибуткових і поширених галузей серед інших галузей світової економіки. Туризм сприяє зміцненню та по- ширенню соціальних, економічних і культурних зв'язків.

Всебічне дослідження аспектів туризму $\epsilon$ актуальною проблемою, яка обумовлена його багатогранністю та суспільною значущістю. Можна впевнено сказати, що туризм став однією з невід'ємних складових життєдіяльності людей у більшості країн світу та є одним iз найперспективніших напрямів соціальноекономічної діяльності у XXI столітті. Варто також зазначити, що туристична діяльність увійшла до найбільших експортних галузей світу та стала найрентабельнішою галуззю світової економіки, що визначає актуальність i практичну значущість проблеми і вимагає всебічного иї вивчення [5].

Значна роль туризму проявляється під час формування морального та культурного рівня суспільства, що випливає із не зацікавлених у плані прибутку масового об'єкта туристичної діяльності. Турист зазвичай сплачує певну суму грошей за туристичні послуги та очікує, що він проведе час пізнавально, а також гарно відпочине. Це створює передумови для того, щоб об'єкт туризму попередньо побудував собі соціальну й культурологічну основу на позитивний результат подорожі, а саме відпочинок, освоєння навколишнього середовища, знайомство 3 менталітетом того чи іншого об'єкта туризму. Внутрішній та зовнішній туризм $\epsilon$ цікавим, вигідним і пізнавальним для туристів по країнах світу [6].

Для надання оперативної інформації потенційному клієнтові про будь-який тур, що 
його цікавить, яка дає можливість швидко і безпомилково вибрати відповідний турпродукт, необхідно оптимізувати функціональний потенціал інформаційної автоматизованої системи [7].

Нині приділяється недостатня увага проблемі ефективного використання інформаційних технологій у туризмі.

Мета дослідження. Метою дослідження було: оптимізувати функціональні можливості та надати обгрунтовані висновки щодо ефективності використання інформаційної системи для розвитку туризму на основі аналізу відвідуваності системи; провести дослідження ефективності обробки даних з боку сервера; обрахувати навантаження на сервер при різних кількостях запитів за секунду за допомогою графіків завантаженості; виявити вразливості та недоліки системи для їх усунення, оптимізувати іiі функціональні можливості.

Опис об'скта і методу дослідження. Важливим фактором у подібних системах $€$ захищеність самої системи, а також даних користувача. Один із методів авторизації має назву basic-authentication, він і використовується в цій системі. Наведений метод використовує тіло Hурertext Transfer Protocol (HTTP) [8] для передачі даних користувача, таких як пароль та електронна пошта, тому цей метод виглядає захищеним, адже запити можна перехопити та отримати дані користувача. Для підвищення захисту системи було проведено оптимізацію та зміну методу авторизації на cookie-authentication, який дає змогу використовувати секретний зашифрований ключ. Таким чином, у випадку перехоплення запиту на сервер дані будуть зашифровані так, що без секретного слова неможливо дізнатися дані користувача. На рисунку 1 зображено форму авторизації цієї системи для розвитку туризму.

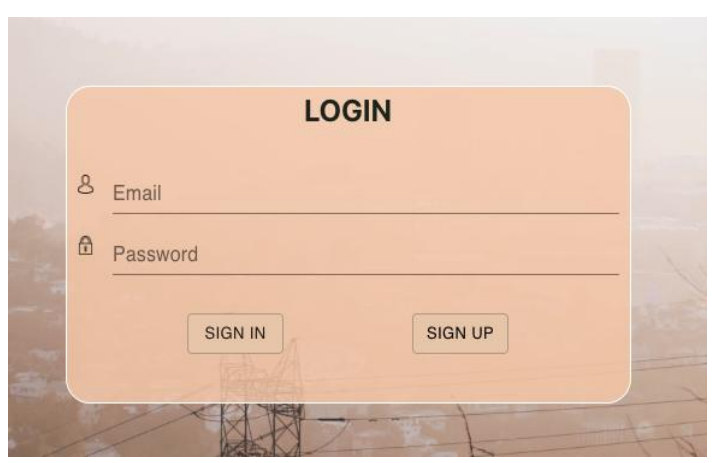

Рисунок 1 - Форма авторизації

«HTTP (Hypertext Transfer Protocol) - це протокол передачі даних, який застосовується для передачі даних у комп'ютерних мережах» [4]. «Протокол для передачі гіпертекстових документів НТТР відноситься до протоколів моделі OSI 7-го прикладного рівня. Головним призначенням протоколу НТТР $є$ передача веб-сторінок, тобто текстових файлів 3 розміткою HTML, за допомогою цього протоколу можна успішно передавати й інші файли, які відносяться до веб-сторінок (зображення та інші медіафайли), також можна передавати файли, не пов’язані з ними» [9].

На рисунку 2 зображено сторінку профілю користувача, де можна побачити особисту інформацію. Також тут можна редагувати особисті дані, добавляти або змінювати фото профілю.

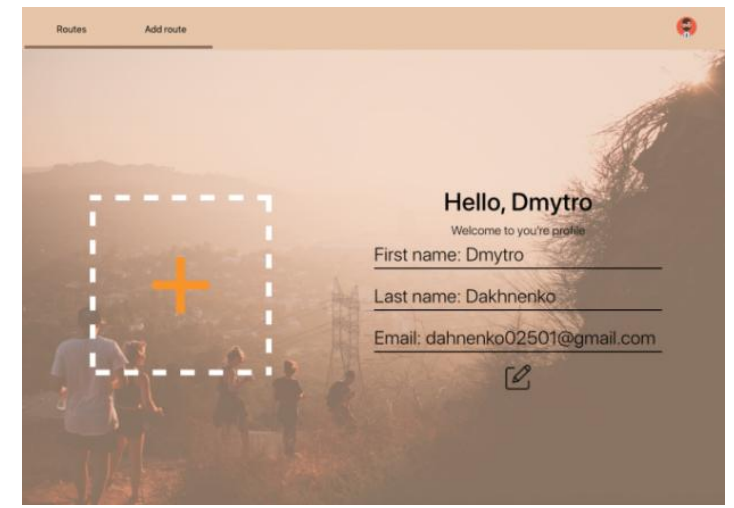

Рисунок 2 - Профіль користувача

3 метою підвищення ефективності потрібно провести рефакторинг.

Рефакторинг - перетворення програмного коду, зміна внутрішньої структури програмного забезпечення для полегшення розуміння коду і легшого внесення подальших змін без зміни зовнішньої поведінки самої системи [10].

На рисунку 3 зображено сторінку додавання маршруту, де можна підписати маршрут, вибрати його тип (прогулянка велосипедом, подорож на машині чи піша прогулянка), добавити опис та позначити на карті сам маршрут.

Мета рефакторингу - зробити код програми більш легким. Рефакторинг відрізняється від оптимізації продуктивності. Як і рефакторинг, оптимізація не змінює саму програму та іï поведінку, а лише прискорює іiі роботу. В свою чергу оптимізація зазвичай ускладнює розуміння самого коду, що не властиво рефакторингу [9-10]. 


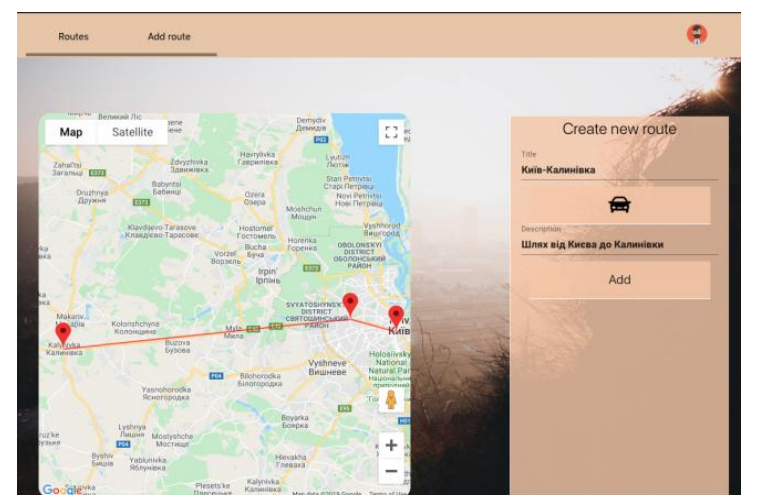

Рисунок 3 - Сторінка створення нових маршрутів

На рисунку 4 зображено перелік усіх доданих користувачами маршрутів (назва, тип маршруту та сам маршрут, відмічений на карті користувачем).

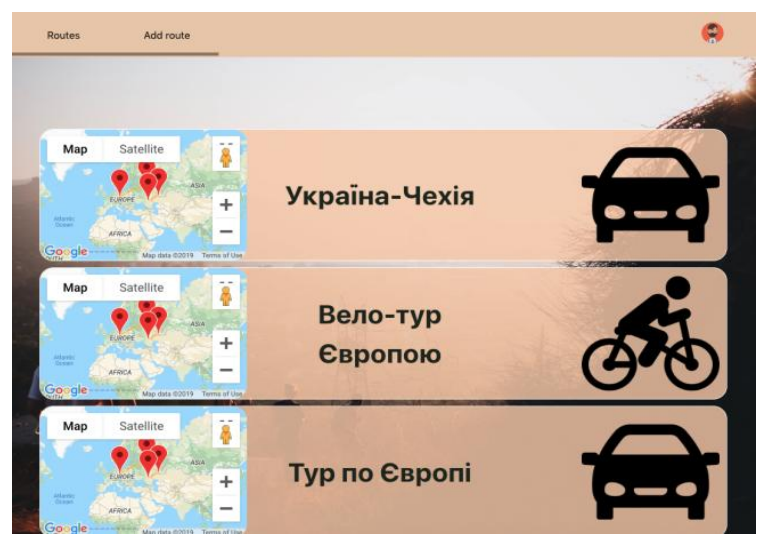

Рисунок 4 - Сторінка переліку всіх маршрутів

Для аналізу відвідуваності користувачами системи було підключено сервіс Google Analytics, що відображає відвідуваність системи користувачами, з якого пристрою той чи інший користувач входив у систему, 3 якої країни та о котрій годині. Сервіс дає можливість аналізу того, що саме привертає увагу користувачів. На основі даних, отриманих від сервісу, було проведено оптимізацію певних ділянок системи.

Google Analytics (GA) - сервіс, який надає компанія Google, призначений для створення детальної статистики відвідувачів певного веб-сайту. Сама статистика створюється з боку сервера самої компанії, все, що потрібно розробнику, - це розмістити JS-код на сторінці свого сайту. Відстеження коду спрацьовує, коли користувач відкриває сторінку в своєму веб-браузері (за умови, якщо користу- вач надасть дозвіл використання Javascript у браузері). В GA інтегровано ще один сервіс компанії Google - AdWords. Особливістю цього сервісу є те, що веб-майстер може оптимізувати рекламні та маркетингові кампанії Google AdWords шляхом аналізу даних, отриманих за допомогою сервісу Google Analytics, про те, звідки приходять відвідувачі (з якого peсурсу), як довго вони знаходяться на сайті та де вони знаходяться географічно. Також доступні додаткові можливості, включаючи поділ відвідувачів на групи, користувачі бачать групи оголошень і віддачу від ключових слів у звітах [11].

«JavaScript (JS) - це асинхронна, не строго типізована, динамічна, об'єктноорієнтована прототипна мова програмування. B мові реалізований стандарт ECMAScript. Використовується переважно для створення ефектів, сценаріїв, побічних ефектів на вебсторінках, що надає можливість 3 боку клієнта (пристрій кінцевого користувача) взаємодіяти 3 користувачем, асинхронно обмінюватися даними 3 сервером, керувати браузером, змінювати структуру та зовнішній вигляд вебсторінки» [12].

Важливим фактором у роботі такої системи є стійкість системи та захищеність від Distributed Denial of Service (DDoS) атак. DDoS - напад на сервіс, систему 3 намірами заблокувати комп'ютерні ресурси для користувачів, які користуються цією системою чи сервісом [12].

Зокрема [13], сукупність взаємопов'язаних даних, що відображає стан об’єктів та їх відносин у розглянутій предметній області і допускає їх використання оптимальним чином для одного або кількох додатків у певній предметній області, являє собою базу даних (БД). У загальному випадку БД містить схеми, таблиці, подання, збережені процедури та інші об'єкти. Дані у базі організовують відповідно до моделі організації даних. Таким чином, сучасна база даних, крім саме даних, містить їх опис і може містити засоби для їх обробки.

База даних $є$ важливим компонентом в архітектурі системи, тому потрібно провести iii аналіз та оптимізацію. В системі використовується база даних MongoDB. 
«MongoDB - це документо-оріснтована система керування базами даних (СКБД) 3 відкритим вихідним кодом, яка не потребуе створення та опису схеми таблиць. Вона займає місце між швидкими і масштабованими системами, які працюють 3 даними у форматі «ключ-значення», а також реляційними СКБД, функціональними і зручними у формуванні запитів» [14].

Система управління базами даних - набір взаємопов'язаних даних (баз даних) і програм для доступу до цих даних. Система надає можливості збереження, створення, оновлення та пошуку інформації в базах даних з контролем доступу до даних.

Опис результатів. Отримані результати від сервісу Google Analytics показали нам, що за тиждень, в середньому, системою користуються 246 користувачів, 3 них 40 - це користувачі смартфонів 3 операційною системою Android, 18 - користувачі смартфонів 3 операційною системою $\mathrm{OOS}$, решта використовують персональний комп'ютер, що зображено на рисунку 5.

Сервіс також показав, що найбільш відвідуваними сторінками користувачів $є$ сторінка створення маршрутів (рисунок 3) і сторінка переліку всіх маршрутів (рисунок 4). Тому на цих сторінках було проведено функціональну оптимізацію та рефакторинг.

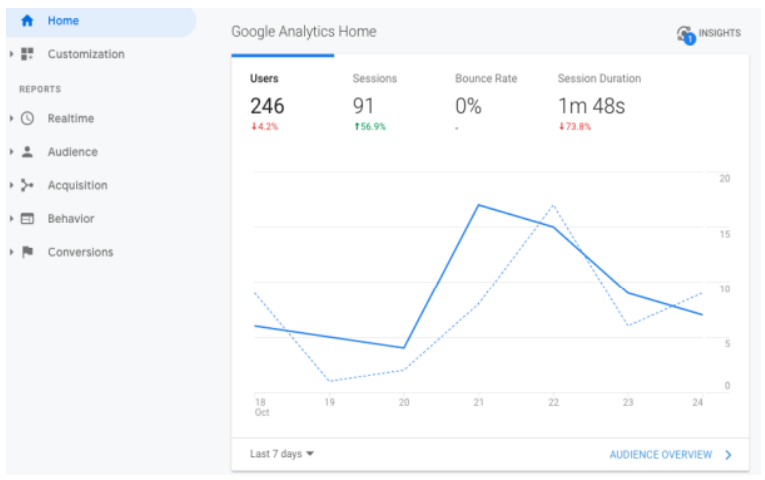

Рисунок 5 - Статистика відвідуваності системи користувачами за тиждень

Отримані дані дають можливість якісно розподілити навантаження сервера на найбільш відвідувані сторінки, а саме - сторінку створення маршрутів (рисунок 3) та сторінку переліку всіх маршрутів (рисунок 4).

Після проведеної оптимізації та рефакторингу коду було отримано статистику 3 но- вими даними. Відтепер відвідуваність системи за тиждень $є$ такою: в середньому, системою користуються 785 користувачів, 3 них 114 - це користувачі смартфонів 3 операційною системою Android, 57 - користувачі смартфонів 3 операційною системою $\mathrm{OOS}$, решта використовують персональний комп'ютер (рисунок 6).

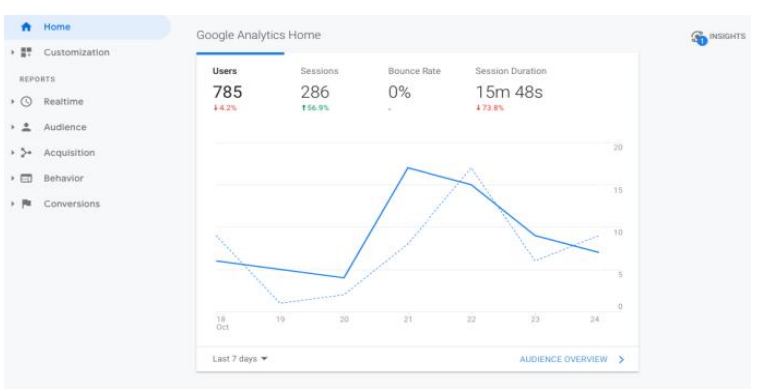

Рисунок 6 - Статистика відвідуваності за тиждень після проведення оптимізації

Наступним кроком був рефакторинг коду, який відповідає за авторизацію в системі, це дає змогу провести заміну методу авторизації на більш захищений. Після рефакторингу було оптимізовано метод авторизації в системі, а саме - замінено метод авторизації basicauthentication на метод cookie-authentication [9-10]. Внаслідок заміни методу процес авторизації користувача став помітно швидшим та надійнішим.

Після проведення аналізу бази даних було виявлено поля і таблиці, які є зайвими та не використовуються в системі. Для того щоб зменшити витрати на зберігання більшої кількості даних, ці поля було видалено.

Під час перевірки коду було знайдено вкладені цикли, які роблять запити до бази даних системи [15]. Такі цикли збільшують навантаження системи, що може призвести до зменшення продуктивності сервера а також вивести СУБД з ладу, тому їх було усунено із системи.

Наступним дуже важливим кроком була перевірка стійкості системи від DDoS атак. Для цього було розроблено систему, яка безперервно робить запити до системи, на той чи інший функціонал. Для першого разу було обрано інтервал 50 запитів в секунду, було використано 330 М (мегабайтів) з лімітованих $838 \mathrm{M}$ (рисунок 7). 


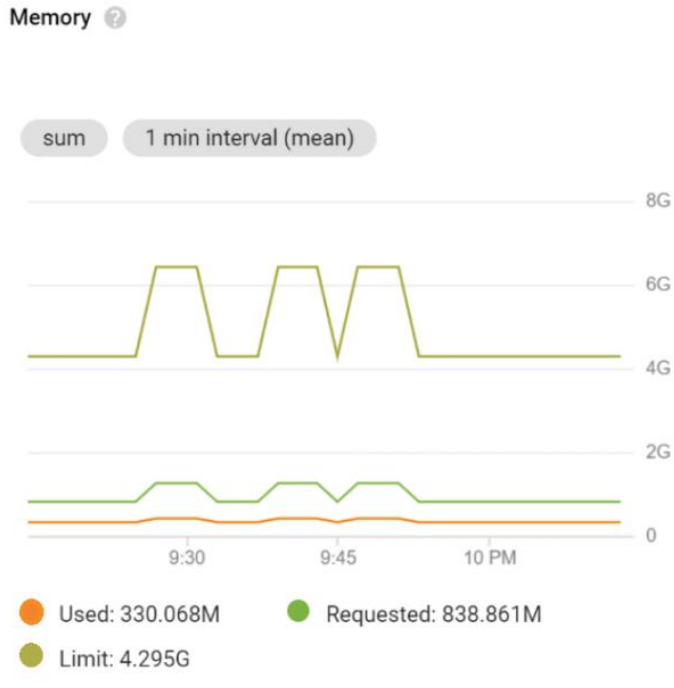

Рисунок 7 - Показники використаної пам'яті при інтервалі 50 запитів у секунду

Наступним було обрано інтервал у 1000 запитів у секунду, після чого система не витримала навантаження i дала збій (рисунок 8).

Використана потужність 1431.985 М більша, ніж відома $1258 \mathrm{M}$.

Для того, щоб захистити нашу систему від DDoS атак, було проведено фільтрування мережі.

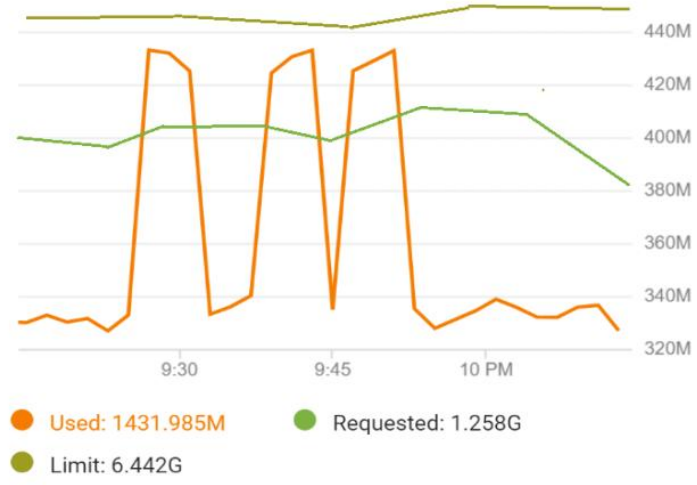

Рисунок 8 - Показники використаної пам'яті при інтервалі 1000 запитів у секунду

Тепер мережа перебирає трафік на себе, обробляє, а також фільтрує його, внаслідок чого до цільового сервера потрапляє тільки відфільтрований, перевірений і якісний трафік від справжніх користувачів. Наступним кроком було автоматичне збільшення потужності серверів шляхом створення нових реплік. Було рознесено активні частини сервера 3 можливістю їх дублювання. При цьому, якщо якась частина ресурсів виявить- ся недоступною, інша частина буде функціонувати. Після завершення цих пунктів провели повторний аналіз системи при 1000 запитах у секунду (рисунок 9).

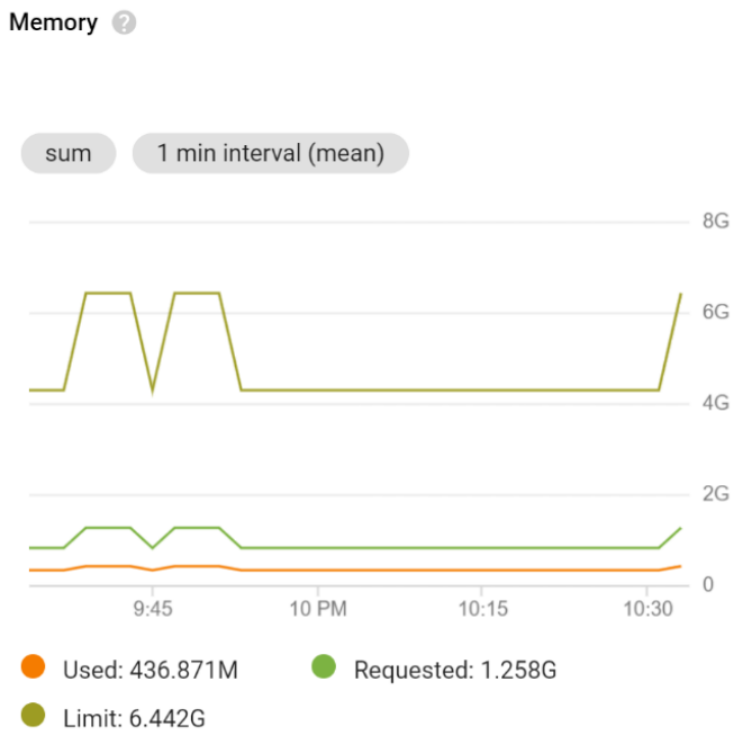

Рисунок 9 - Показники використаної пам'яті при інтервалі 1000 запитів у секунду після оптимізації

Висновки. Шляхом чисельних оптимізацій, проведених для підвищення ефективності використання інформаційної автоматизованої системи щодо розвитку туризму, було удосконалено іiї функціонал, що дало можливість стверджувати: оптимізована система розрахована на підвищене навантаження та справляється 3 DdoS-атаками, а проведення часткового рефакторингу на сторінках створення та переліку маршрутів забезпечило підвищення чисельності користувачів цієї розробленої та оптимізованої інформаційної системи.

\section{Список літератури}

[1] О. В. Грицунов, Інформаційні системи ma технологї: навч. посіб. Харків: ХНАМГ, 2010.

[2] В. I. Ящук, "Аналіз сучасного стану інформаційних технологій та систем в індустрії туризму". Вісник Львівського торговельно-економічного університету. Економічні науки, вип. 53, с. 56-60, 2017.

[3] Н. Н. Кормягина, "Smart-туризм как часть Smart-концепции", Маркетинг и логистика: науч.-практ. журн., вып. 6 (14), c. 45-57, 2017. 
[4] С.В.Мельниченко, "Інформаційні технології в туризмі: теоретичні та практичні аспекти". Вісник Запорізького національного університету, № 2 (6), с. 129-138, 2010.

[5] Ю. Б. Миронов, та I. І. Свидрук. "Туризм як чинник економічного розвитку країни", Науковий вісник НЛТУ України (Львів), вип. 26.6, с. 255-262, 2016.

[6] Туризмологія: концептуальні засади теоpiï туризму: наук.-навч. вид. Київ: КУТЕП, 2008.

[7] В. П. Гаврилов, Інформаційні системи $i$ технології в туризмі: навч. посіб. для студентів напряму підготовки 6.140103 "Туризм". Харків: ХНЕУ ім. С. Кузнеця, 2016. ISBN: 978-966-676-645-1.

[8] David Gourley, Brian Totty, Marjorie Sayer, Anshu Aggarwal, and Sailu Reddy, HTTP The Definitive Guide, O'Reilly. ISBN: 9781565925090

[9] Р. Мартин, Чистый код. Создание, анализ и рефакторинг. Санкт-Петербург: Питер, 2013. ISBN: 9785446100699.

[10] М. Фаулер, Рефакторинг: улучшение существующего кода, пер. с англ. СанктПетербург: Символ-Плюс, 2003. ISBN: 593286-045-6. [Электронный ресурс]. Режим доступа: https://fktpm.ru/file/61fauler-refactoring-refaktoring-uluchsheniesuschestvujuschego-koda.pdf

[11] Брайан Клифтон, Google Analytics для профессионалов, 3-е изд., "Диалектика", 2013. ISBN: 978-5-8459-1797-3,

[12] David R. Brooks, An introduction to PHP for scientists and engineers: beyond JavaScript. Moscow: Springer, 2008.

[13] П. В. Бураков, и В. Ю. Петров, Введение в системы баз данных: учеб. пособ. СанктПетербург, 2010.

[14] Kristina Chodorow, MongoDB: the definitive guide. Moscow, 2010.

[15] Р. В. Киричок, "Тест на проникнення як імітаційний підхід до аналізу захищеності корпоративних інформаційних систем", Сучасний захист інформаџїі, № 2 (34), 2018. ISSN: 2409-7292.

\section{References}

[1] O. V. Gritsunov, Information systems and technologies: textbook. Kharkiv: KhNAMG, 2010 [in Ukrainian].

[2] V. I. Yashchuk, "Analysis of the current state of information technologies and systems in the tourism industry", Visnyk Lvivskoho torhovelno-ekonomichnoho universytetu. Ekonomichni nauky, iss. 53, pp. 56-60, 2017 [in Ukrainian].

[3] N. N. Kormyagina, "Smart tourism as a part of the Smart concept", Marketing i logistika: sci.-pract. journ., iss. 6 (14), pp. 45-57, 2017 [in Russian].

[4] S. V. Melnichenko, "Information technologies in the tourism: theoretical and practical aspects", Visnyk Zaporizkoho natsionalnoho universytetu, no. 2 (6), pp. 129-138, 2010 [in Ukrainian].

[5] Yu. B. Mironov, and I. I. Svidruk, "Tourism as a factor of country's economic development", Naukovyi visnyk NLTU Ukrainy (Lviv), iss. 26.6, pp. 255-262, 2016 [in Ukrainian].

[6] Tourism: conceptual foundations of tourism theory: sci. ed. Kyiv: KUTEP, 2008 [in Ukrainian].

[7] V.P. Gavrylov, Information systems and technologies in tourism: textbook. Kharkiv: KhNEU im. S. Kuznets, 2016. ISBN: 978966-676-645-1 [in Ukrainian].

[8] David Gourley, Brian Totty, Marjorie Sayer, Anshu Aggarwal, and Sailu Reddy, HTTP The Definitive Guide, O'Reilly. ISBN: 9781565925090.

[9] R. Martin, Clean code. Creation, analysis and refactoring. St. Petersburg: Peter, 2013. ISBN: 9785446100699 [in Russian].

[10] M. Fowler, Refactoring: improving the existing code, transl. from Engl. St. Petersburg: Symbol-Plus, 2003. ISBN: 5-93286045-6. [Online]. Available: https://fktpm.ru/ file/61-fauler-refactoring-refaktoringuluchshenie-suschestvujuschego-koda.pdf

[11] Brian Clifton, Google Analytics for professionals, 3rd ed., "Dialectics", 2013. ISBN: 978-5-8459-1797-3 [in Russian].

[12] David R. Brooks, An introduction to PHP for scientists and engineers: beyond JavaScript. Moscow: Springer, 2008.

[13] P. V. Burakov, and V. Yu. Petrov, Introduction to database systems: textbook. St. Petersburg, 2010 [in Russian].

[14] Kristina Chodorow, MongoDB: the definitive guide. Moscow, 2010.

[15] R. V. Kirichok, "Penetration test as a simulation approach to the analysis of security of corporate information systems", Suchasnyi zakhyst informatsii, no. 2 (34), 2018. ISSN 2409-7292 [in Ukrainian]. 


\author{
S. V. Sysoienko, $P h . D$., \\ e-mail: s.sysoienko@gmail.com \\ D. V. Dakhnenko, master \\ e-mail: dahnenko02501@gmail.com \\ Cherkasy State Technological University \\ Shevchenko blvd, 460, Cherkasy,18006, Ukraine

\section{OPTIMIZATION OF FUNCTIONAL OPPORTUNITIES OF INFORMATION SYSTEM FOR TOURISM DEVELOPMENT}

The research gives the possibility to optimize the functionality of information automated system for tourism development. The research has shown that the speed of page loading and data processing of the server is an important factor in the process of optimization. As a result of the research and optimization, the statistics on the attendance of this system, as well as the effectiveness of the system have been obtained, the advantages and disadvantages have been identified. After the optimization of the system, the shortcomings are eliminated, as well as the efficiency and attendance of information system for tourism development are increased. The specific features of the creation and implementation of tourist services (a large number of participants and their significant geographical separation, extensive system of relations between the subjects of tourist market, territorial differentiation of tourist product, the distance of the place of sale of tourist services from the place of their consumption) determine the need for research and optimization of the functionality of information system for tourism development. Tourism, as an important segment of foreign trade, envisages export-import operations with services and is one of the sources of attraction of foreign currency into the country. The subfunction of payments balance means a comparison of tourist expenditures of the local population who have gone abroad (outbound tourism, import of services), with the income derived from the consumption of goods and services by foreign nationals who have arrived in the country for tourist purposes (inbound tourism). In this case, the export of tourist services is specific and is often called "invisible" exports, since the tourist product is consumed, as a rule, at the point of service.

Keywords: optimization, research, system for tourism development, statistics, database, authorization, refactoring.

Стаття надійшла 18.11.2019

Прийнято 05.12.19

(C) С. В. Сисоєнко, Д. В. Дахненко, 2019

DOI: $10.24025 / 2306-4412.4 .2019 .184140$ 